\title{
FACTORS INFLUENCING LEISURE TIME PHYSICAL ACTIVITY OF CHILDREN
}

\author{
Vidmantas Katasanovas, Vytautas Katasanovas, Žilvinas Stankevičius \\ Lithuanian Sports University, Kaunas, Lithuania
}

\begin{abstract}
ANNOTATION
The article discusses what factors influence leisure time physical activity physical activity of children. Qualitative methods were used in this article performing comparative analysis of scientific literature. Scientific articles discussing results of empirical research were chosen for the analysis. Research reveals that two main groups of factors can be treated as significant in affecting physical activity of children: psychosocial factors, and factors of social support (family, home, school). Neighbourhood environmental and facility factors are not relevant to explain children's and adolescents' physical activity.
\end{abstract}

Keywords: leisure time, physical activity, children, adolescents.

\section{INTRODUCTION}

Relevance of theme. There is no doubt about the importance of physical activity in all age groups of population, and its positive effect on human health. Physical activity may be suggested as one of the main needs of human body, to keep its health and immunity in optimal level. Scientists especially care about health of children. Modern life style goes along with insufficient levels of physical activity that became an obvious tendency not only among adults, but also among children (Ziviani et al., 2008). Rates of childhood and adolescent overweight and obesity are rising around the world (Lam, McHale, 2015), so there is a need of appropriate intervention to encourage children to be more physical active. Physical activity is an important component of any health promotion program (Rezende et al., 2014). In such a situation it is important to discuss all the aspects related to the ways that could encourage children for physical activity, including the analysis of factors, influencing their leisure time physical activity.

Research problem. In order to choose the right means to encourage children to be more physical active, it is important to analyse what factors can influence this. Leisure time is an important routine of children's everyday life, and engaging into physical activities during leisure time brings a lot of benefits, so it is important to analyse what factors influence children's leisure time physical activity.

Problem exploration. Problem of minimising levels of physical activity physical activity of children is widely researched, and it was discussed in publications by J. L. Hernandez-Alvarez, et al. (2009), Ch. B. Lam and S. M. McHale (2015), J. Ziviani et al. (2008), L. Haerens et al. (2009), S. C. Dumith et al. (2011). Factors influencing leisure time physical activity of children were discussed in many researches. Important research in Lithuanian context was performed by J. Armonienè (2007). For the analysis of research problem the results of researched performed by L. Haerens et al. (2009), Ch. B. Lam and S. M. McHale (2015), L. F. Rezende et al. (2014), Y. J. Chen et al. (2011), J. Ziviani et al. (2008), D. van Dyck et al. (2014), J. Ziviani et al. (2008), L. Haerens, et al. (2009), and others are important. Scientists explain factors influencing leisure time physical activity physical activity of children on the basis of Social-Cognitive Theory (developed by Bandura, 
1986) or / and ecological models (discussed by van Dyck et al., 2014; Ziviani et al., 2008). It can be noticed that separate researched find rather different results, so it is important to summarise results of these separate scientifically researched and theoretically compare what factors are more important for children leisure time physical activity, and what factors are less important. Such summarising of previous results of empirical researches results is suggested in this article.

Goal of research - to analyse factors influencing leisure time physical activity physical activity of children.

\section{Objects of research:}

1. To discuss importance of leisure time physical activity for children;

2. To identify groups of factors important for children leisure time physical activity physical activity.

Research object subject - factors influencing leisure time physical activity physical activity of children.

Methodology of research. Qualitative methods were used in this article, performing comparative analysis of scientific literature. Scientific articles discussing results of empirical research were chosen for the analysis. Most articles that are analysed were published in 2007-2015. It was chosen to analyse articles, talking about physical activity of children, using the definition of a „child” as a person under age 18 , so the analysis includes researches about physical activity of adolescents as well.

\section{RESULTS OF RESEARCH}

Concept of physical activity. There is a variety of definitions of physical activity. R. Jankauskienè (2008) suggests that it is "Body movements, results of which is higher energy consumption that in condition of rest"; A. Jansoniene et al. (2012) defines it as aerobic endurance, coordination abilities, and R. M. Malina et al. (2004) defines physical activity as "Any body movement produced by the skeletal muscles, that results in a substantial increase over the resting energy expenditure". Summarising the definitions it can be said, that physical activity is all the body movements that require energy expenditure. That means that physical activity changes the state of body. Physical activity may appear in many ways, forms and context that include free play, house chores, exercise, school physical education, and organized sport (Malina et al., 2004).

Importance of leisure time physical activity. Physical activity is important for children's health, and health is described as "all-around physical, spiritual, mental, emotional and social wealth of individual and society" (Armonienè, 2007). Many scientific researches prove the importance of physical activity for health, and that there is a risks to person's health if physical activity is not sufficient. Physical activity has positive effects on reduction in risks for all-cause mortality: cardiovascular diseases (Amireault, Godin, 2015), diabetes, hypertension, hyperlipidemia, some forms of cancer (Gallagher et al., 2013), also reduction of depressive symptoms, and body weight (also the illnesses that are stimulated by obesity.

Many authors (Ziviani et al., 2008; Haerens et al., 2009; Dumith et al., 2011; etc.) emphasize a problem of growing physical inactivity of children, also growing levels of obesity related to this in 
well developed countries. The live style of modern population becomes more and more sedentary (Dunton et al., 2007), and this is followed by lower levels of physical activity. The results of different studies in European countries show the presence of a high percentage of the population whose physical activity is insufficient, and this is a danger to population's health (Hernandez- Alvarez et al., 2009). Children and adolescents are usually more physically active than adults (Lam, McHale, 2015), unfortunately, S. C. Dumith et al. (2011), generalising 26 studies, found that adolescents' physical activity levels decrease linearly over time. Some longitudinal studies found that physical activity of boys is declining more rapidly than physical activity of girls (Lam, McHale, 2015), however, overall physical activity of girl is lower than the one of boys (Hernandez-Alvarez et al., 2009). Besides is should be stated that active leisure should follow a curvilinear pattern of change: is increases during middle childhood, when children play a lot, and decreasing across adolescence, when adolescent spend more time at home or at school engaging into intellectual activity, and leisure that contains no playing elements (Galambos et al., 2009). This explains why problem of insufficient physical activity is especially important for adults, and it is more important in the adolescence than in earlier childhood.

Leisure time physical activity is especially important for adults and children, as it may provide the greatest opportunity for enjoyment and improvement in fitness- and health-related benefits (Amireault, Godin, 2015). Leisure time physical activity is the main way that adolescents incorporate physical activity into their daily lives (Rezende et al., 2014). According to J. Ziviani et al. (2008), ,,interests, skills, confidence and participation patterns in physical activity are established early in life, and these patterns frequently continue into adulthood", and it must be understood that physical activity and normal fitness of body may be considered as a participation pattern, also as obesity and physical inactivity. Forming right participation patters and interest in childhood, there is a higher expectancy of their endurance into adulthood. M. Menai et al. (2015) state that active transportation, such as walking and cycling in everyday life is now considered as a key element of physical activity promotion for health, and an important part of leisure time physical activity. In the line with these statements it can be said that leisure time physical activity is especially important for children for overall benefit of physical activity for their physical and mental health (in childhood and in future), and physical activity should be a part of leisure time routine, assuring that children would be physically active daily.

Factors influencing leisure time physical activity of children. There are theories that explain why and how people engage in activities of physical activity. According to J. Ziviani et al. (2008), L. Haerens et al. (2009), D. van Dyck et al. (2014), physical activity may be explained in the context of social - cognitive theory and ecological model's theory.

The Social-Cognitive Theory (SCT; Bandura, 1986) "posits psychosocial concepts to explain health behaviour change", there exist some self-regulation of physical activity, related to persons perceived enjoyment (i.e., reinforcement), self-efficacy beliefs, decisional balance (assessment of positive and negative outcome expectancies), and social support (Ziviani et al., 2008). This theory explained what factors influence the physical activity of a person (Haerens et al., 2009). It is believed, that psychological (personal, internal) factors of physical activity are especially important to predict amount of leisure time physical activity, and also they are important planning the interventions of 
public policy seeking to encourage leisure time physical activity (Gallagher et al., 2013). It can be said that these factors are divided into two main groups: internal factors (perceived enjoyment (i.e., reinforcement), self-efficacy beliefs, decisional balance) and external factors (social support that also means the support by family, school and other direct social environment).

Ecological models of physical activity behaviour emphasise importance of individual, social, physical environmental (such as neighbourhood walkability, street connectivity, mixed land use, access to recreation facilities and aesthetics, etc.) and political factors activity (van Dyck et al., 2014). Researches reveal that issues of town planning, build environment can encourage of discourage physical activity of children and adults, for example, a ,lack of access to public transport and sporting facilities coupled with a high reliance on vehicular transport" (Ziviani et al., 2008). In short, ecological models add two groups of factors that are not overviews by social-cognitive theory physical environmental and political factors.

Summarising these two theories explaining factors influencing leisure time physical activity such groups of factors may be determined: psychosocial factors (internal factors), environmental factors including factors of social support (family, school), physical environment and political factors (referring to the idea that political mind determined that environmental factors of physical activity is created). These groups of factors are discussed below.

Psychosocial factors. D. van Dyck et al. (2014) empirically researched interactions between psychosocial and environmental correlates of leisure-time physical activity in three-country study. Results reveal that psychosocial attributes have independent contribution explaining recreational walking and leisure-time physical activity, gender and site may have moderating effects. Also enjoyment, perceived social support from family and friends, perceived benefits, and self-efficacy have positive associations with leisure time physical activity, and perceived barriers were negatively associated. Perceived barriers and perceived social support from friends are strong psychosocial correlates to intensive physical activity.

Psychological state is very important. P. Gallagher et al. (2013) found out that extraversion, conscientiousness and lower standing on neuroticism are positively correlated with more leisure time physical activity leisure time physical activity. Empirical results also reveal that psychosocial attributes may have different influence to leisure time physical activity in different cultural or environmental context, not only different countries, but also different regions of the same large country (like different regions of United states) (Chen et al., 2011).

There are some gender differences that are explained by traditional gender roles that are getting stronger during adolescence: sport is related to masculine qualities such as strength, competitiveness, and assertiveness, and there is a strong decline of girls' physical activity related to these stereotypes (Lam, McHale, 2015). Also ecological models explain some gender-specific results: social support from family is more important for women than men, but unexpectedly (van Dyck et al., 2014). Leisure time physical activity was greater among adolescents residing in rural municipalities, males, those younger than 13 years (Rezende et al., 2014).

Some researchers also reveal the importance of socioeconomic factors for children's leisure time physical activity. L. F. Rezende et al. (2014) suggest that socioeconomic status usually assures 
better availability of sport's inventor, and mote qualitative nutrition for adolescents. J. Ziviani et al. (2008) stated that children from the low socio-economical areas spent more time playing at home and in their neighbourhoods than children from higher socio-economical areas. Children from the low socio-economical areas are less able to afford access to commercial physical-activity amenities. These authors also suggest that for children in their early school years these factors do not influence their level of physical activity, but it may have difference in adolescent age, so as children get older, there is a great benefit of structured activities of physical activity, such as sport clubs, basketball or tennis courts, football fields etc. Is was found by A. E. Bauman et al. (2012) that socioeconomically disadvantaged families may not be able to afford youth involvement in certain physical activity, but this factor is significant considering adolescents' professional sports activities, and any physical activity of young adults.

Summarising these finding it can be said, that psychological factors, such as extraversion, conscientiousness, enjoyment, self-efficacy are related to higher levels of physical activity. Gender also matters - boys are usually more physically active that girls, especially there are great differences in adolescence. Influence of socioeconomic factors is not obvious: smaller children's physical activity does not correlate to financial state of family, but better financial state may lead to more active physical activity in adolescence and youth.

Family life and home environment. Theoretical parental socialization model explain how parents influence their children's physical activity, distinguishing these parental actions (Simpkins et al., 2012): 1. Modelling - being physically active themselves; 2 . Encouragement and reinforcement praising children for being physically active; 3. Provision of opportunities - enrolling children in sports and outdoor activities; 4. Joint involvement - engaging in sports and outdoor activities with children. Much empirical research supports that these factors are important to motivate children's leisure time physical activity (Lam, McHale, 2015). However Ch. B. Lam and S. M. McHale (2015) argue that the influence of parents should not be overemphasised, and should be explained also analysing internal psychological factors and within-person associations of physical activity.

Not only influence and support of parents matter, but also physical home environment. L. Haerens et al. (2009) reveal that the availability of sedentary equipment, for instance, video games equipment at home, discourage adolescents from going outside and being physically active, and this negative influence of sedentary equipment is especially strong for boys. Influence of such equipment for girls is rather weak. It may be explained that video and computer games are more interesting for boys than girls, and playing such games is considered as rather masculine activity.

It can be said that parents may have great influence on children's physical activity modelling, encouraging, providing and involving their children with physical activities. But children's physical activity is negatively influenced if home surroundings encourage sedentary leisure time activities.

School. J. Armonienè (2007) has found out that pedagogical factors, such as daytime table, leisure, business, are also important for stimulating pupils' physical activity. Scholl has to organise the process of learning in such a way that physical activity would be stimulated- physical and intellectual charge should be normed rationally, pupils should be given a natural opportunity to move, conditions for work and leisure should be organizes properly, they should be encouraged to keep the 
time table. Also results of research performed by L. Haerens et al. (2009) demonstrate that school environment and participation in extracurricular activities at school are important in stimulating children's leisure time physical activity. These authors suggest that the time spent in extracurricular activities at school contributes considerably to overall physical activity levels, and school may base its intervention creating to the availability of organized activities at school. Such organized physical activity activities at school are especially influential for girls. Boys tend to spend their leisure time more actively physically than girls if no organized forms are suggested (especially in adolescence), so it is important to pay attention how to encourage girls to be physically active. Other researches also suggest that offering extra physical activities at school is an effective strategy for increasing physical activity of children and adolescents (Haug et al., 2008). Researchers also state the importance of supervision while engaging into extracurricular activities; it was demonstrated that there is a stronger correlation between supervision and engagement in extracurricular activities among boys (Hamilton, White, 2008).

In summary, efforts of school to create availability of organized physical activities at school, with supervision, also rational daytime table, giving children time for being physically active, may have benefit on the levels of physical activity of children.

Neighbourhood environmental and physical facility factors. Different studies have shown that interventions in public spaces, with easily accessible facilities and proper guidance, affect individual choices to engage in physical activity (Parra et al., 2011). Providing appropriate public spaces lowers the physical, psychological, and financial barriers to leisure time physical activity (Ferreira et al., 2007). Conducting programs at plazas, parks, and beaches, or even along avenues or in places near homes, encourages greater participation by the population (Ding et al., 2011). However these finding more describe situation with adults, not children. Researches reveal that perceptions of residential density, proximity of destinations (land use mix-diversity) and aesthetics are import for adults to engage into such activities of physical activity as recreational walking, o running outsides, but not for children (Saelens et al., 2012). Similar results are located in earlier researches. Results of research performed by L. Haerens et al. (2009) (research performed in American, Canadian, Norwegian context) reveal that neighbourhood environmental factor, such as the perceived convenience of facilities, is important for adults to engage in physical activities, but not for children of adolescents. But there are some exceptions when the perceived convenience of sport and other physical activity facilities is important for girls' adolescents (but not boys). A. L. Oyeyemi et al. (2014) examined four neighbourhood environmental factors: access to facilities, availability of facilities, availability of equipment, crime incidence. Authors reveal that availability and access to facilities and equipment (access to parks, recreation facilities and street connectivity) is consistently unrelated to physical activity of adolescents, as well as neighbourhood safety levels. Even on the contrary as expected, crime incidence appeared to be inversely associated with adolescents' physical activity in some studies (Ding et al., 2011).

According to ecological models of behaviour change, the environment does not influence behaviour separate from individual determinants (Haerens et al., 2009). According to results of 
research P. Gallagher et al. (2013) argue that children's physical activity correlates with several personality and situational factors:

- Extraversion, Conscientiousness and lower standing on Neuroticism are positively correlated with more leisure time physical activity leisure time physical activity;

- People routinely report several environmental or logistical factors, such as lack of time, poor weather, lack of facilities, and parenthood are barriers to leisure time physical activity.

These two groups of factors are related; higher levels of Extraversion, Conscientiousness my help people to overcome environment barriers to leisure time physical activity (Gallagher et al., 2013). A. L. Oyeyemi et al. (2014) suggest that the influence of the physical environment on physical activity levels of adolescents might not be direct and could be mediated by other levels of control including psychosocial factors (e.g., self-efficacy, social support and perceived benefits and barriers).

It can be concluded that neighbourhood environmental and facility factors are not relevant to explain children's and adolescents' physical activity. In the context of what was discussed above, two main groups of factors can be treated as significant in affecting physical activity of children: psychosocial factors, and factors of social support (family, home, school).

\section{CONCLUSIONS AND PERSPECTIVES}

1. In modern society a problem of growing physical inactivity of children is emphasised, growing levels of obesity is related to this. Leisure time physical activity is especially important for children for overall benefit of physical activity for their physical and mental health (in childhood and in future), and physical activity should be a part of leisure time routine, assuring that children would be physically active daily.

2. Talking about psychosocial factors, it was revealed that psychological factors, such as extraversion, conscientiousness, enjoyment, and self-efficacy are related to higher levels of physical activity. Gender also matters - boys are usually more physically active that girls (especially there are great differences in adolescence). Influence of socioeconomic factors is not obvious (smaller children's physical activity does not correlate to financial state of family, but it does in later age). Parents may have great influence on children's physical activity modelling, encouraging, providing and involving their children with physical activities. But children's physical activity is negatively influenced if home surroundings encourage sedentary leisure time activities. Efforts of school to create availability of organized physical activities at school, with supervision, also rational daytime table, giving children time for being physically active, may have benefit on the levels of physical activity of children. However neighbourhood environmental and facility factors are not relevant to explain children's and adolescents' physical activity.

In future researches it could be discussed how psychosocial, social support factors interrelate each other and what their overall effect of children physical activity is. Also it could be research how different factors influence children's physical activity in different stages of childhood. 


\section{REFERENCES}

1. Amireault, S., Godin, G. (2015). The godin-shephard leisure-time physical activity questionnaire: Validity evidence supporting its use for classifying healthy adults into active and insufficiently active categories. Perceptual \& Motor Skills: Physical Development \& Measurement, 120 (2), 604-622.

2. Armonienė, J. (2007). Mokinių fizinis aktyvumas ir sveikata. Pedagogika, 85, 116-121.

3. Bauman, A. E., Reis, R. S., Sallis, J. F. et al. (2012). Correlates of physical activity: Why are some people physically active and others not? Lancet, 380, 258-271.

4. Berge, J. M., Larson, N., Bauer, K. W. et al. (2011). Are parents of young children practicing healthy nutrition and physical activity behaviors? Pediatrics, 127, 881-887.

5. Chen, Y. J., Huang, Y. H., Lu, F. H. et al. (2011). The correlates of leisure time physical activity among an adults population from Southern Taiwan. BMC Public Health, 11, 427.

6. Ding, D., Sallis, J. F., Kerr, J. et al. (2011). Neighbourhood environment and physical activity among youth: a review. American Journal of Preventive Medicine, 41 (4), 442-455.

7. Dumith, S. C., Gigante, P. D., Domingues, R. M. et al. (2011). Physical activity change during adolescence: A systematic review and a pooled analysis. International Journal of Epidemiology, 40, 685-698.

8. Dunton, G. L., Schneider, M., Cooper, D. M. (2007). An investigation of psychosocial factors related to changes in physical activity and fitness among female adolescents. Psychology and hHealth, 22 (8), 929 944.

9. van Dyck, D., Cerin, E., Conway, T. L. et al. (2014). Interacting psychosocial and environmental correlates of leisure-time physical activity: A three-country study. Health psychology, 33 (7), 699-709.

10.Ferreira, I., van der Horst, K., Wendel-Vos, W. et al. (2007). Environmental correlates of physical activity in youth - a review and update. Obesity Reviews, 8, 129-154.

11.Galambos, N. L., Berenbaum, S. A., McHale, S. M. (2009). Gender development in adolescence. In R. M. Lerner \& L. Steinberg, Handbook of Adolescent Psychology: Vol. 1. Individual Bases of Adolescent Development (pp. 305-357). Hoboken, NJ: Wiley.

12.Gallagher, P., Yancy, W. S., Denissen, J. J. A. et al. (2013). Correlates of daily leisure-time physical activity in a community sample: Narrow personality traits and practical barriers. Health psychology, 32 (12), $1227-1235$.

13.Haerens, L., De Bourdeaudhuij, I., Barba, G. et al. (2009). Developing the IDEFICS communitybased intervention program to enhance eating behaviors in 2- to 8-year-old children: Findings from focus groups with children and parents. Health Education Research, 24 (3), 381-339.

14.Hamilton, K., White, K. M. (2008). Extending the theory of planned behaviour: The role of self and social influences in predicting adolescent regular moderate-to-vigorous physical activity. Journal of Sport and Exercise Psychology, 30 (1), 56-74.

15.Haug, E., Torsheim, T., Samdal, O. (2008). Physical environmental characteristics and individual interests as correlates of physical activity in Norwegian secondary schools. International Journal of Behavioral Nutrition and Physical Activity, 5, 45-54. 
16.Hernandez-Alvarez, J. L., Velazquez- Buendia, R., Martinez- Gorrono, M. E. et al. (2009). Lifestyle and physical activity in Spanish children and teenagers: The impact of psychosocial and biological factors. Journal of Applied Biobehavioral Research, 14 (2), 55-69.

17.Jankauskienè, R. (2008). Lietuvos gyventojų fizinio aktyvumo skatinimo strategija: kūno kultūra ar kūno kultas? Medicina, 44 (5), 346-355.

18.Jansonienė A., Šapokienè, L., Paliušienè, V., Skužinskienė, A. (2012). KTU pirmo kuro studentu fizinio rengimo ir sveikatos stiprinimo programų efektyvumas. Sportini darbinguma lemiantys veiksniai (V): moksliniu straipsniu rinkinys (pp. 60-65). Kaunas.

19.Lam, Ch. B., McHale, S. M. (2015). Developmental patterns and parental correlates of youth leisuretime physical activity. Journal of Family psychology, 29 (1), 100-107.

20.Malina, R. M., Bouchard, C., Bar-Or, O. (2004). Growth, Maturation, and Physical Activity. Human Kinetics.

21.Menai, M., Charreire, H., Feuillet, F. et al. (2015). Walking and cycling for commuting, leisure and errands: Relations with individual characteristics and leisure-time physical activity in a cross-sectional survey. Journal of Behavioral Nutrition and Physical Activity, 12, 1-10.

22.Oyeyemi, A. L., Ishaku, C. M., Deforche, B. et al. (2014). Perception of built environmental factors and physical activity among adolescents in Nigeria. International Journal of Behavioral Nutrition and Physical Activity, 11 (56), 1-21.

23.Parra, D. ., Hoehner, C. M., Hallal, P. C. et al. (2011). Perceived environmental correlates of physical activity for leisure and transportation in Curitiba, Brazil. Preventive Medicine, 52, 234-238.

24.Rezende, L. F., Azeredo, C. M., Canella, D. S. et al. (2014). Sociodemographic and behavioral factors associated with physical activity in Brazilian adolescents. BMC Public Health, 14, 1-24.

25.Saelens, B. E., Sallis, J. F., Frank, L. D. et al. (2012). Neighbourhood environment and psychosocial correlates of adults' physical activity. Medicine \& Science in Sports \& Exercise, 44, 637-646.

26.Simpkins, S. D., Fredricks, J. A., Eccles, J. S. (2012). Charting the Eccles' expectancy-value model from mothers' beliefs in childhood to youths' activities in adolescence. Developmental Psychology, 48, 10191032 .

27. Ziviani, J., Wadley, D., Ward, H. et al. (2008). A place to play: Socioeconomic and spatial factors in children's physical activity. Australian Occupational Therapy Journal, 55, 2-11. 


\title{
FACTORS INFLUENCING LEISURE TIME PHYSICAL ACTIVITY OF CHILDREN
}

\author{
Vidmantas Katasanovas, Vytautas Katasanovas, Žilvinas Stankevičius
}

Lithuanian Sports University, Kaunas, Lithuania

\begin{abstract}
Grounding of research. Scientific problem discussed in the article - what factors influence children's leisure time physical activity. In order to choose the right means to encourage children to be more physical active, it is important to analyse what factors can influence this. Leisure time is an important routine of children's everyday life, and engaging into physical activities during leisure time brings a lot of benefits. The problem is relevant as it is important to discuss all the aspects related to the ways that could encourage children for physical activity, including the analysis of factors, influencing their leisure time physical activity. The goal of research - to analyse factors influencing leisure time physical activity physical activity of children. Objects of research: To discuss importance of leisure time physical activity for children; To identify groups of factors important for children leisure time physical activity physical activity. Research object subject- factors influencing leisure time physical activity physical activity of children. Qualitative methods were used in this article, performing comparative analysis of scientific literature. Scientific articles discussing results of empirical research were chosen for the analysis. Most articles that are analysed were published in 2007-2015.
\end{abstract}

Results of research. Results of research reveal that leisure time physical activity is especially important for children for overall benefit of physical activity for their physical and mental health (in childhood and in future). According to the theories explaining factors influencing leisure time physical activity such groups of factors may be determined: psychosocial factors (internal factors), environmental factors including factors of social support (family, school), physical environment and political factors. Results reveal that psychological factors, such as extraversion, conscientiousness, enjoyment, self-efficacy are related to higher levels of physical activity. Gender also matters - boys are usually more physically active that girls (especially there are great differences in adolescence). Influence of socioeconomic factors is not obvious (smaller children's physical activity does not correlate to financial state of family, but it does in later age). Parents may have great influence on children's physical activity modelling, encouraging, providing and involving their children with physical activities. But children's physical activity is negatively influenced if home surroundings encourage sedentary leisure time activities. Efforts of school to create availability of organized physical activities with supervision, also rational daytime table, giving children time for being physically active, may have benefit. However neighbourhood environmental and facility factors are not relevant to explain children's and adolescents' physical activity.

Main conclusions of research. 1. Physical activity should be a part of leisure time routine, assuring that children would be physically active daily. 2. Two main groups of factors can be treated as significant in affecting physical activity of children: psychosocial factors, and factors of social support (family, home, school). Neighbourhood environmental and facility factors are not relevant to explain children's and adolescents' physical activity. In the context of what was discussed above.

Keywords: leisure time, physical activity, children, adolescents. 